\title{
Doppler Pulsatility Index in Spontaneous Intracerebral Hemorrhage
}

\author{
Ines C. Kiphuth ${ }^{a}$ Hagen B. Huttner ${ }^{a}$ Arnd Dörfler ${ }^{b}$ Stefan Schwab ${ }^{a}$ \\ Martin Köhrmann ${ }^{\text {a }}$ \\ Departments of a Neurology and ${ }^{b}$ Neuroradiology, University of Erlangen-Nuremberg, Erlangen, Germany
}

\begin{abstract}
Key Words
Transcranial duplex sonography $\cdot$ Pulsatility index $\cdot$ Midline shift · Intracerebral hemorrhage $\cdot$ Functional outcome
\end{abstract}

\begin{abstract}
Background and Purpose: Elevated intracranial pressure (ICP) as a result of intracerebral hemorrhage (ICH) and perihematomal edema often leads to tissue shift, which can be identified in cross-sectional imaging and presents a known predictor of functional outcome. Pulsatility indices (PIs) of the intracranial arteries as measured by transcranial Doppler sonography (TCD) may serve as surrogate parameters for ICP. This study aims to investigate whether PI correlates with ICP and midline shift and serves as a reliable predictor of functional outcome in patients with ICH. Methods: Within a 1-year period between April 2009 and April 2010, 136 patients with acute spontaneous, supratentorial ICH were admitted to our tertiary care hospital. One-hundred and twenty-four patients fulfilled the inclusion criteria and were eligible for analysis. TCD and transcranial duplex sonography were performed on admission and at least once more during hospital stay. Functional outcome was assessed 6 months after discharge. Correlation analyses, logistic regression analyses and receiver operating characteristic curves were calculated. Results: One-hundred and twenty-four patients were included in the analysis. Six-month mortality amounted to $39.5 \%$. The ICH score and Pls of the middle cerebral artery were independent predictors of outcome 6 months
\end{abstract}

\section{KARGER}

E-Mail karger@karger.com

www.karger.com/ene after discharge. Conclusions: Early PI monitoring by TCD correlated with ICP and may be used to predict the outcome after 6 months.

Copyright $\odot 2013$ S. Karger AG, Basel

\section{Introduction}

Spontaneous intracerebral hemorrhage (ICH) is associated with severe morbidity and a 30 -day mortality rate of up to $55 \%$ [1]. Possible complications include hematoma growth, perihematomal edema and intraventricular hemorrhage [1]. These complications may lead to elevated intracranial pressure (ICP), either primarily through an increase in intracranial volume or secondarily through acute obstructive hydrocephalus. Reduction in elevated ICP maintaining values $<20 \mathrm{~mm} \mathrm{Hg}$ is the major therapeutic target to prevent potentially life-threatening cerebral hypoperfusion [1-5]. ICP can be monitored indirectly by cross-sectional imaging as well as directly by ventriculostomy and microtransducers [6]. However, marked and clinically relevant ICP gradients may exist within the supratentorial department [7-11], possibly resulting in locally rather than globally measured ICP.

Transcranial Doppler (TCD) and duplex sonography (TDS) present noninvasive, inexpensive bedside tools to diagnose and monitor intracranial pathology such as midline shift (MLS), cerebral artery flow velocities and, in special cases, hematoma volume [12-15] and is therefore

Dr. med. Ines Christine Kiphuth 
Fig. 1. a MLS evaluated by TDS: insonation through the left temporal bone window. $\mathrm{V} 3=$ Third ventricle; $\mathrm{T}=$ thalamus; $\mathrm{B}=$ dis tance between the right tabula of the skull and the middle of the third ventricle. $\mathbf{b}$ Distance from the left/right tabula of the skull/ TDS probe and the middle of the third ventricle $(\mathrm{A} / \mathrm{B})$.

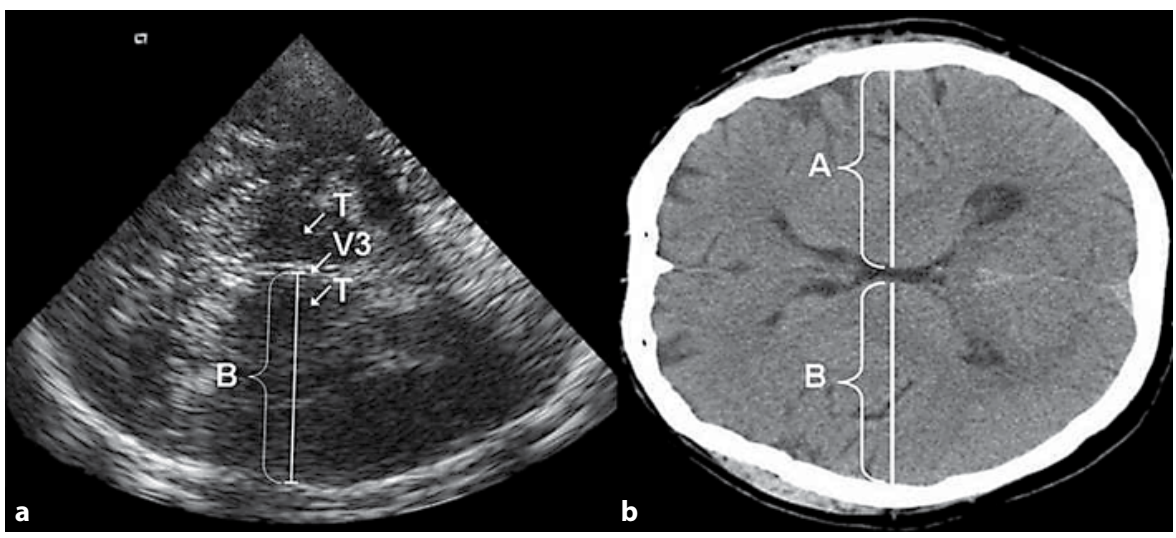

applicable in patients with cerebral ischemia, subarachnoid hemorrhage and ICH $[12,13,15-18]$. Furthermore, elevated ICP may be detected by increased PI [19], which is not only more easily accessible than direct ICP measurement through ventriculostomy or microtransducers in the majority of patients but may also represent the ICP of a larger part of the supratentorial compartment due to the course of the respective intracranial vessel.

This study aims to investigate whether PI measured by TCD is a valid surrogate for ICP and whether PI correlates with functional outcome after 6 months in patients with supratentorial ICH.

\section{Materials and Methods}

\section{Patients and ICH Management}

This study was performed at a tertiary University Hospital (Erlangen, Germany). All patients with spontaneous, supratentorial ICH who were admitted between April 2009 and April 2010 were eligible. One-hundred and thirty-six patients were screened. Twelve patients were not enrolled due to the following exclusion criteria: insufficient temporal bone window $(n=3)$, early hematoma growth $(\mathrm{n}=4)$ and hematoma evacuation $(\mathrm{n}=5)$. Patients with hematoma growth and/or hematoma evacuation were excluded since the change in intracranial volume would have prejudiced the prediction analysis.

ICH management was carried out according to EUSI recommendations [20]. Hematoma volume was calculated from cardiac CT (cCT), as previously described $[21,22]$. Hematoma growth was defined as an increase of more than $33 \%$ in the parenchymal hematoma volume compared to the baseline hematoma volume [23].

\section{Outcome Assessment}

Functional outcome was evaluated 6 months after discharge using the modified Rankin Scale (mRS). The mRS was assessed by a semistructured telephone interview by a certified interviewer with the patient or - if the patient was unable to talk on the phone - the legal guardian.
Standard Protocol Approval, Registration and Patient Consent

Consent to participate in this study was obtained from all patients or their relatives/legal guardians. The study was approved by the local ethics committee.

\section{Neurosonologic Methods}

All TCD examinations were carried out by a dedicated trial team independent of the clinical team. All investigators were experienced neurosonologists and are certified for neurological vascular ultrasound by the German Ultrasound Society. TCD was conducted within $24 \mathrm{~h}$ of symptom onset, after 3-6 days and again after 8-12 days with a conventional Doppler system (SONARA/ tek, Medilab, Würzburg, Germany) equipped with a 2-MHz pulsed wave probe. Whenever possible, TCD was conducted just before cross-sectional imaging. Within the standardized study protocol, the middle cerebral artery was examined on both sides between depths of 45 and $65 \mathrm{~mm}$. PI was calculated (systolic velocity - diastolic velocity/mean flow velocity) and judged normal if values between 0.5 and 1.19 were reached [24]. The maximum PI in the middle cerebral artery was entered in the analysis.

TDS was performed at the same time points as the TCD examinations with a phased-array ultrasound system equipped with a $1.33-\mathrm{MHz}$ transducer (Siemens Acuson Antares) through the contralateral temporal bone window as described before [12, 18]. The third ventricle was visualized in a depth of $6-8 \mathrm{~cm}$ and identified by its parallel hyperechogenic margins and the surrounding hypoechogenic thalami. The distance between the probe and the margins of the third ventricle were measured in perpendicular lines. The deviation from the presumed midline was measured by the equation $(\mathrm{a}-\mathrm{b}) / 2$ (fig. 1) [18].

\section{Statistics}

Statistical tests were two-sided and the significance level was set at $\alpha=0.05$. The distribution of the data was assessed with the Kolmogorov-Smirnov test. Continuous and categorical variables are expressed as the mean and SD, interquartile range, or as percentage, as appropriate. We performed forward step-wise logistic regression analyses as well as receiver operating characteristic (ROC) curves with functional outcome (mRS 0-2, mRS 3-6) and mortality at 6 months after discharge as the dependent variables. All statistical analyses were calculated with the SPSS 17.0 software package (SPSS Inc., Chicago, Ill., USA). 
Table 1. Demographic and clinical data of all patients and depending on functional outcome after 6 months



Figures in parentheses are percentages; figures in brackets are interquartile ranges. LOS = Length of stay; LOV = length of ventilation; loco typ = loco typico.

\section{Results}

During a 1-year period, 124 patients with spontaneous ICH were enrolled in this study. The median National Institutes of Health stroke scale on admission was 18, the mean hematoma volume was $28 \mathrm{~cm}^{3}$. The demographic and clinical data of the patients are given in table 1. Mortality 6 months after discharge amounted to $39.5 \%$.

\section{Correlation of PI and ICP and MLS, Respectively}

Fifty-nine patients received invasive ICP monitoring (via ventriculostomy, $\mathrm{n}=56$, or microtransducer, $\mathrm{n}=3$ ). PI was correlated with ICP during the examination. A total of 137 examinations were analyzed (59 at admission, 54 between day 3 and day 6 , and 24 between day 8 and day 12). The correlation of PI with ICP was high $(r=0.712)$. Additionally, the correlation of PI and MLS was calculated in those patients $(\mathrm{n}=85)$ who had cross-sectional imaging (cCT or cardiac MRI) within $1 \mathrm{~h}$ of TCD (49 at admission, 27 between day 3 and day 6 , and 9 between day 8 and day 12). The correlation of PI and MLS was high $(r=0.645)$.

\section{Predictors of Functional Outcome}

The parameters age, sex, length of hospital stay and hematoma location did not show statistically significant differences between survivors and nonsurvivors. The following parameters were significantly associated with mortality in the univariate analysis: higher National Institutes of Health stroke scale on admission, prolonged length of ventilation, ventricular involvement of $\mathrm{ICH}$, larger ICH volume, increased MLS on admission and follow-up examinations, higher ICH score and higher PI of the affected and unaffected hemisphere on admission and follow-up examinations. Furthermore, PI was associated with a poor outcome (mRS 3-6) and mortality. The results of the multivariate logistic regression analysis depending on functional outcome are given in table 2. MLS was not included in the multivariate analysis since our calculations showed that MLS and PI closely correlate with each other in this patient cohort.

\section{Sensitivity, Specificity, Positive and Negative}

Predictive Values for Mortality

ROC analyses (specificity and sensitivity) as well as positive and negative predictive values for critical PI values, indicating mortality after 6 months, were calculated. ROC analyses showed that PI predicted for mortality within 6 months after discharge. The results of the ROC analyses as well as the positive predictive values and negative predictive values depending on PI cut-off values are given in table 3 .

\section{Discussion}

Formation of perihemorrhagic edema is dynamic [25, 26], may last up to 14 days [27] and may peak in the early as well as in the subacute phase $[18,28]$, leading to an 
Table 2. Multivariate logistic regression analysis depending on mRS 6 months after discharge

\begin{tabular}{|c|c|c|c|c|c|c|c|c|c|}
\hline & \multicolumn{3}{|l|}{ mRS 0-2 } & \multicolumn{3}{|l|}{ mRS 3-6 } & \multicolumn{3}{|l|}{ mRS 6} \\
\hline & $\operatorname{Exp}($ coef) & $95 \% \mathrm{CI}$ & $\mathrm{p}$ & Exp (coef) & $95 \% \mathrm{CI}$ & $\mathrm{p}$ & Exp (coef) & $95 \% \mathrm{CI}$ & $\mathrm{p}$ \\
\hline Length of ventilation & 0.852 & $0.384-1.952$ & 0.184 & 1.037 & $0.638-2.825$ & 0.732 & 1.227 & $1.097-1.484$ & 0.156 \\
\hline PI highest ever, ipsilateral & 0.117 & $0.012-1.238$ & 0.079 & 1.871 & $1.017-3.954$ & 0.046 & 3.991 & $2.054-7.264$ & $<0.001$ \\
\hline
\end{tabular}

Statistically significant predictors are given in italics. CI = Confidence interval.

increase in ICP that can cause subfalcial and uncal herniation. However, increased ICP may not only appear directly as tissue shift which can be imaged in cross-sectional imaging or TDS, but also indirectly as decreased enddiastolic flow velocity leading to characteristic changes in the Doppler waveform and increased PI [29] (fig. 2).

This prospective study is solely based on ultrasound imaging. PI is known to vary depending on the resistance of the supplied tissue, the diastolic velocity of the basal cerebral arteries decreasing in case of increased ICP and thus elevating the PI [14]. Furthermore, age can cause the vessels to loose compliance; hence, older people may have increased PIs, independently of increased ICP. In order to rule out old age as an underlying reason for increased PI in our cohort, we compared the PIs of patients older and younger than 65 years, after adjusting for MLS and hematoma volume, and found no significant difference concerning PI and age. Intracranial tissue shift is generally monitored by serial cCT scans. However, this involves the repeated transportation of critically ill, possibly ventilated and unstable patients, which may lead to complications in up to 70\% [30]. Alternatively, intracranial MLS can be reliably monitored by TDS with a high interand intraobserver reliability $[13,31,32]$, thus providing a noninvasive, bedside alternative to $\mathrm{CCT}$.

In this study, normal ipsilateral PI as well as slight to moderate elevation of PI (PI <1.75) indicated that the patient survived the follow-up period (negative predictive value $>80 \%$; table 3 ), whereas initial high PI (PI $>2.0$ ) had a high predictive value of $>96 \%$ for mortality within 6 months of discharge. Our data are in line with the results of previous studies showing that the PI as well as MLS serve as predictors of functional outcome [29, 33, 34].

TDS is an inexpensive, bedside tool that can easily be implemented and interpreted.

The main fields of application are the detection of stenoses of the basal cerebral arteries and the evaluation of vasospasms [35, 36]. Furthermore, TDS measurement
Table 3. Sensitivity (\%), specificity (\%), positive and negative predictive values (\%) of day 0 and the highest PI of the affected hemisphere, respectively, for mortality after 6 months

\begin{tabular}{ccccc}
\hline Cut-off PI & Sensitivity & Specificity & PPV & NPV \\
\hline Day 0 (AUC & 0.856 , CI & $0.779-0.932)$ & & \\
1.25 & 83.7 & 46.7 & 50.6 & 81.4 \\
1.35 & 83.7 & 65.3 & 61.2 & 86.0 \\
1.45 & 79.6 & 74.7 & 67.2 & 84.8 \\
1.55 & 77.6 & 90.7 & 84.4 & 86.1 \\
1.65 & 65.3 & 92.0 & 84.2 & 80.2 \\
1.75 & 65.3 & 93.3 & 86.5 & 80.5 \\
1.85 & 61.2 & 96.0 & 90.9 & 79.1 \\
2.00 & 57.1 & 98.7 & 96.6 & 77.9 \\
2.15 & 53.1 & 100.0 & 100.0 & 76.5 \\
Highest (AUC 0.886, CI $0.823-0.949)$ & & \\
1.45 & 91.8 & 46.7 & 52.9 & 89.7 \\
1.55 & 87.8 & 61.3 & 59.7 & 88.5 \\
1.70 & 85.7 & 72.0 & 66.7 & 88.5 \\
1.85 & 77.6 & 82.7 & 74.5 & 84.9 \\
1.95 & 71.4 & 88.0 & 79.5 & 82.5 \\
2.05 & 71.4 & 92.0 & 85.4 & 83.1 \\
2.15 & 67.3 & 96.0 & 91.7 & 81.8 \\
2.35 & 65.3 & 96.0 & 91.4 & 80.9 \\
2.55 & 61.2 & 97.3 & 93.8 & 79.3 \\
\hline
\end{tabular}

$\mathrm{PPV}=$ Positive predictive value; $\mathrm{NPV}=$ negative predictive value; $\mathrm{AUC}=$ area under the curve; $\mathrm{CI}=$ confidence interval.

can be used in the assessment of brain death [37]. In the present study, we measured PI and MLS as surrogate parameters for increased ICP at different time points, covering the initial and subacute phase of edema formation. In comparison to invasive ICP monitoring, which may lead to complications such as hemorrhage and infection [38-40], PI monitoring is noninvasive, and thus, does not cause complications. Moreover, costs of ventriculostomy and the installation of microtransducers by far exceed those of TCD. However, ICP monitoring via 

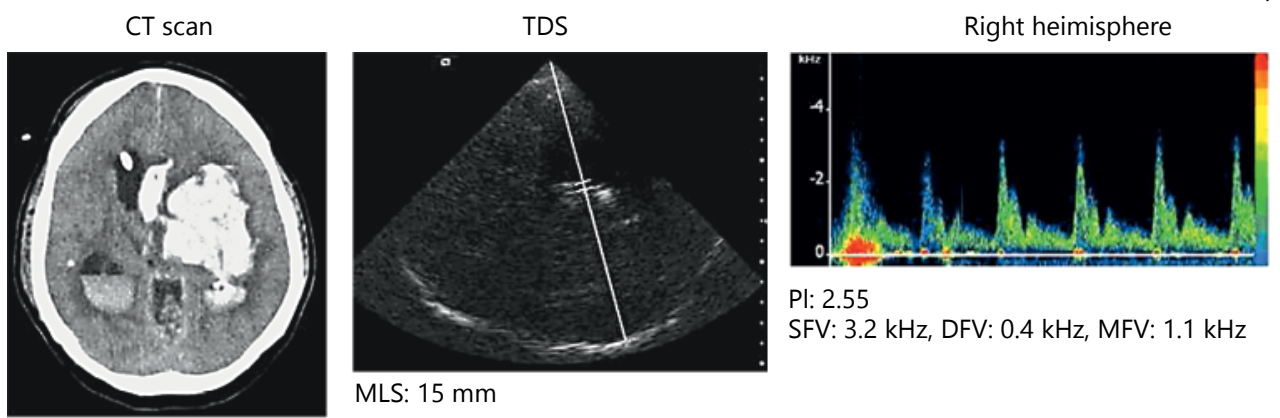

PI: 2.55

SFV: $3.2 \mathrm{kHz}$, DFV: $0.4 \mathrm{kHz}, \mathrm{MFV}: 1.1 \mathrm{kHz}$

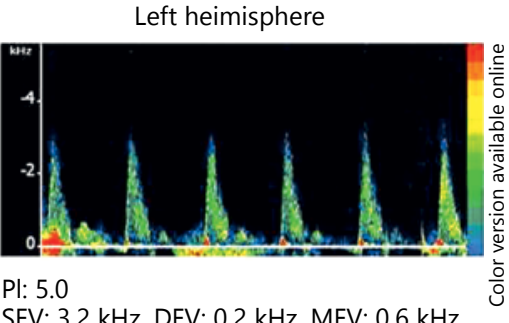

MLS: $15 \mathrm{~mm}$
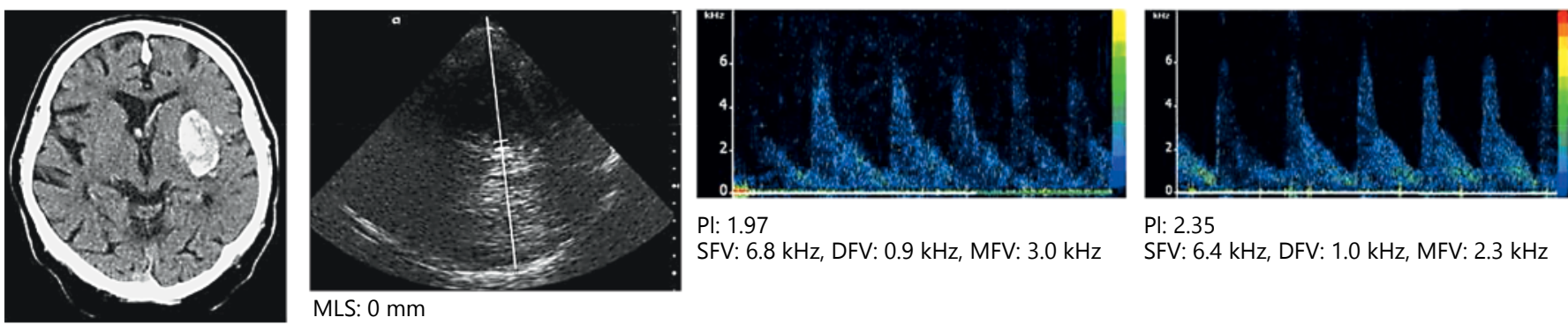

PI: 1.97

SFV: 6.8 kHz, DFV: 0.9 kHz, MFV: $3.0 \mathrm{kHz}$

Pl: 2.35

MLS: $0 \mathrm{~mm}$
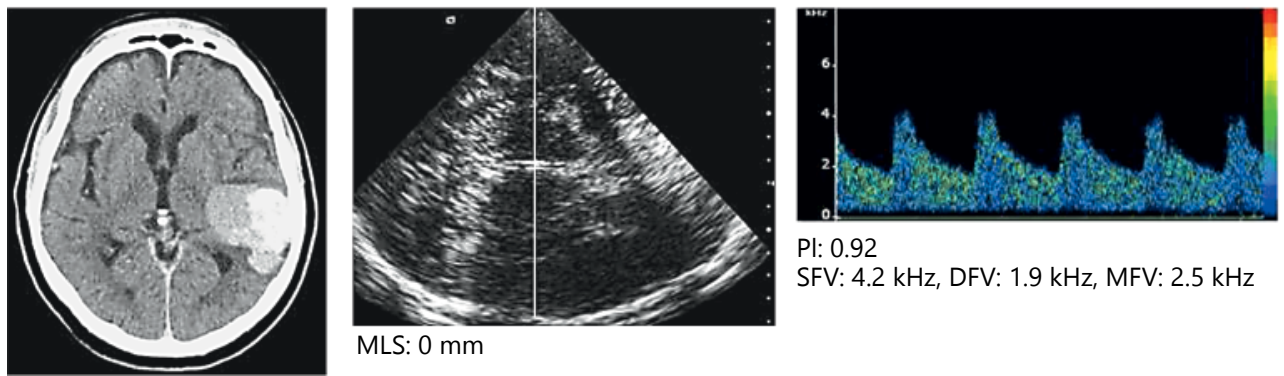

PI: 0.92

SFV: $4.2 \mathrm{kHz}$, DFV: $1.9 \mathrm{kHz}, \mathrm{MFV}: 2.5 \mathrm{kHz}$

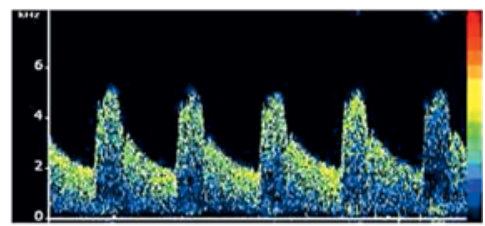

PI: 0.97

SFV: $6.3 \mathrm{kHz}$, DFV: $2.0 \mathrm{kHz}, \mathrm{MFV}: 3.2 \mathrm{kHz}$

MLS: $0 \mathrm{~mm}$

Fig. 2. CT scans, TDS and TCD of patients with different characteristic forms of ICH and the according Doppler waveform changes and increased PIs. TDS was performed through the right temporal bone window in each case. SFV = Systolic flow velocity; DFV = diastolic flow velocity; MFV = mean flow velocity.

TCD is less accurate than invasive monitoring and while extraventricular drains and microtransducers measure ICP continually - ICP monitoring by TCD covers only a limited time period. Thus, ICP monitoring by PI may not replace invasive ICP monitoring, but may be of diagnostic help in patients with suspected elevated ICP who are not suitable for direct ICP measurement or in which the indication to apply direct ICP measurements is questionable.

Limitations of our study comprise the small patient number and the single-center design. Furthermore, monitoring of PI and MLS by ultrasound depends on the existence of sufficient temporal bone windows, which will always present an obstacle in intracranial ultrasound, even though this restriction becomes less frequent with the advances of ultrasound technology.

\section{Conclusion}

This prospective ultrasound study shows a high correlation between PI and MLS and ICP, respectively. Therefore, we suggest that TCD may be used as a screening parameter for patients with ICH in risk of ICP elevation in addition to the usual monitoring. Furthermore, measurement of PI and MLS may serve as reliable though indirect tools to predict mortality at 6 months.

\section{Disclosure Statement}

There is no conflict of interest. 


\section{References}

1 Balami JS, Buchan AM: Complications of intracerebral haemorrhage. Lancet Neurol 2012;11:101-118

2 Morgenstern LB, Hemphill JC 3rd, Anderson $\mathrm{C}$, et al: Guidelines for the management of spontaneous intracerebral hemorrhage: a guideline for healthcare professionals from the American Heart Association/American Stroke Association. Stroke 2010;41:21082129.

3 Bratton SL, Chestnut RM, Ghajar J, et al: Guidelines for the management of severe traumatic brain injury. 8. Intracranial pressure thresholds. J Neurotrauma 2007;24(suppl 1):S55-S58.

4 Bratton SL, Chestnut RM, Ghajar J, et al: Guidelines for the management of severe traumatic brain injury. 7. Intracranial pressure monitoring technology. J Neurotrauma 2007;24(suppl 1):S45-S54.

5 Bratton SL, Chestnut RM, Ghajar J, et al: Guidelines for the management of severe traumatic brain injury. 6. Indications for intracranial pressure monitoring. J Neurotrauma 2007;24(suppl 1):S37-S44.

6 Raboel PH, Bartek J Jr, Andresen M, Bellander BM, Romner B: Intracranial pressure monitoring: invasive versus non-invasive methods - a review. Crit Care Res Pract 2012;2012: 950393.

7 Chambers IR, Kane PJ, Signorini DF, Jenkins A, Mendelow AD: Bilateral ICP monitoring: its importance in detecting the severity of secondary insults. Acta Neurochir Suppl 1998; 71:42-43.

8 Sahuquillo J, Poca MA, Arribas M, Garnacho A, Rubio E: Interhemispheric supratentorial intracranial pressure gradients in head-injured patients: are they clinically important? J Neurosurg 1999;90:16-26.

9 Bekar A, Taskapilioglu O, Yilmazlar S, Ender $\mathrm{K}$, Aksoy K: Is supratentorial pressure difference clinically relevant? Analysis of 55 consecutive cases by bilateral intracranial pressure monitoring. Neurol Res 2008;30:465470 .

10 Weaver DD, Winn HR, Jane JA: Differential intracranial pressure in patients with unilateral mass lesions. J Neurosurg 1982;56:660665.

11 Piek J, Plewe P, Bock WJ: Intrahemispheric gradients of brain tissue pressure in patients with brain tumours. Acta Neurochir 1988;93: 129-132.

12 Gerriets T, Stolz E, Konig S, et al: Sonographic monitoring of midline shift in space-occupying stroke: an early outcome predictor. Stroke 2001;32:442-447.
13 Perez ES, Delgado-Mederos R, Rubiera M, et al: Transcranial duplex sonography for monitoring hyperacute intracerebral hemorrhage. Stroke 2009;40:987-990.

14 Nicoletto HA, Burkman MH: Transcranial Doppler series part III: interpretation. Am J Electroneurodiagnostic Technol 2009;49: 244-259.

15 Sutherland BA, Minnerup J, Balami JS, Arba F, Buchan AM, Kleinschnitz C: Neuroprotection for ischaemic stroke: translation from the bench to the bedside. Int J Stroke 2012;7:407418.

16 Kiphuth IC, Huttner HB, Struffert T, Schwab S, Kohrmann M: Sonographic monitoring of ventricle enlargement in posthemorrhagic hydrocephalus. Neurology 2011;76:858-862.

17 Kiphuth IC, Huttner HB, Breuer L, Engelhorn T, Schwab S, Kohrmann M: Vasospasm in intracerebral hemorrhage with ventricular involvement: a prospective pilot transcranial Doppler sonography study. Cerebrovasc Dis 2011;32:420-425

18 Kiphuth IC, Huttner HB, Breuer L, Schwab S, Köhrmann M: Sonographic monitoring of midline shift predicts outcome after intracerebral hemorrhage. Cerebrovasc Dis 2012;34: 297-394.

19 Prunet B, Asencio Y, Lacroix G, et al: Noninvasive detection of elevated intracranial pressure using a portable ultrasound system. Am J Emerg Med 2012;30:936-941.

20 Steiner T, Kaste M, Forsting M, et al: Recommendations for the management of intracranial haemorrhage - part I: spontaneous intracerebral haemorrhage. The European Stroke Initiative Writing Committee and the Writing Committee for the EUSI Executive Committee. Cerebrovasc Dis 2006;22:294-316.

21 Kothari RU, Brott T, Broderick JP, et al: The ABCs of measuring intracerebral hemorrhage volumes. Stroke 1996;27:1304-1305.

22 Divani AA, Majidi S, Luo X, et al: The ABCs of accurate volumetric measurement of cerebral hematoma. Stroke 2011;42:1569-1574.

23 Brott T, Broderick J, Kothari R, et al: Early hemorrhage growth in patients with intracerebral hemorrhage. Stroke 1997;28:1-5.

24 Katz ML, Alexandrov AV: A Practical Guide to Transcranial Doppler Examinations. Littleton, Summer Publishing, 2003, pp 25-48.

25 Gebel JM Jr, Jauch EC, Brott TG, et al: Natural history of perihematomal edema in patients with hyperacute spontaneous intracerebral hemorrhage. Stroke 2002;33:2631-2635.

26 Inaji $\mathrm{M}$, Tomita $\mathrm{H}$, Tone $\mathrm{O}$, Tamaki M, Suzuki R, Ohno K: Chronological changes of perihematomal edema of human intracerebral hematoma. Acta Neurochir Suppl 2003; 86:445-448.
27 Butcher KS, Baird T, MacGregor L, Desmond $\mathrm{P}$, Tress B, Davis S: Perihematomal edema in primary intracerebral hemorrhage is plasma derived. Stroke 2004;35:1879-1885.

28 Venkatasubramanian C, Mlynash M, FinleyCaulfield A, et al: Natural history of perihematomal edema after intracerebral hemorrhage measured by serial magnetic resonance imaging. Stroke 2011;42:73-80.

29 Marti-Fabregas J, Belvis R, Guardia E, et al: Prognostic value of pulsatility index in acute intracerebral hemorrhage. Neurology 2003; 61:1051-1056.

30 Waydhas C: Intrahospital transport of critically ill patients. Crit Care 1999;3:R83-R89.

31 Becker G, Bogdahn U, Strassburg HM, et al: Identification of ventricular enlargement and estimation of intracranial pressure by transcranial color-coded real-time sonography. J Neuroimaging 1994;4:17-22.

32 Seidel G, Kaps M, Gerriets T, Hutzelmann A: Evaluation of the ventricular system in adults by transcranial duplex sonography. J Neuroimaging 1995;5:105-108.

33 Tang SC, Huang SJ, Jeng JS, Yip PK: Third ventricle midline shift due to spontaneous supratentorial intracerebral hemorrhage evaluated by transcranial color-coded sonography. J Ultrasound Med 2006;25:203-209.

34 Fogelholm R, Murros K, Rissanen A, Avikainen S: Long term survival after primary intracerebral haemorrhage: a retrospective population based study. J Neurol Neurosurg Psychiatry 2005;76:1534-1538.

35 Tang SC, Jeng JS, Yip PK, et al: Transcranial color-coded sonography for the detection of middle cerebral artery stenosis. J Ultrasound Med 2005;24:451-457, quiz 9-60.

36 Rasulo FA, De Peri E, Lavinio A: Transcranial Doppler ultrasonography in intensive care. Eur J Anaesthesiol Suppl 2008;42:167-173.

37 Hassler W, Steinmetz H, Gawlowski J: Transcranial Doppler ultrasonography in raised intracranial pressure and in intracranial circulatory arrest. J Neurosurg 1988;68:745-751.

38 Camacho EF, Boszczowski I, Basso M, et al: Infection rate and risk factors associated with infections related to external ventricular drain. Infection 2011;39:47-51.

39 Kim JH, Desai NS, Ricci J, et al: Factors contributing to ventriculostomy infection. World Neurosurg 2012;77:135-140.

40 Lemcke J, Depner F, Meier U: The impact of silver nanoparticle-coated and antibiotic-impregnated external ventricular drainage catheters on the risk of infections: a clinical comparison of 95 patients. Acta Neurochir Suppl 2012;114:347-350. 